\title{
Investigating Building Information Modelling (BIM) Adoption in Indonesia Construction Industry
}

\author{
Jati Utomo Dwi Hatmoko*, Yulian Fundra, Mochamad Agung Wibowo and Zhabrinna \\ Department of Civil Engineering, Diponegoro University, Semarang, Indonesia
}

\begin{abstract}
The development of information technology continues to evolve to respond the increasing demand and challenges in the construction industry. Building Information Modelling (BIM) emerges in recent years as the fresh solution to make the project lifecycle more efficient by encouraging collaborative working of all stakeholders involved in the construction project, i.e. owners, consultants, and contractors. This study aims to investigate BIM adoption and implementation in Indonesia construction industry and explore challenges and opportunities related to the implementation of BIM. A combination of qualitative and quantitative research method has been adopted for this exploratory research. Data was collected through interviews and questionnaires survey with snowball sampling from twenty entities, consisting of 12 contractors, 4 consultants, and 4 owners. The results show that $60 \%$ of respondents have already acknowledged and implemented BIM. The examples of BIM software used by the respondents include Revit, Tekla, and SmartPlan ${ }^{\circledR}$. Benefits of BIM implementation as perceived by most respondents, e.g. design collision detection, clear project simulation, reduced reworks, and efficient use of resources. The adoption of BIM, however, still faces challenges, such as the absence of requirement and demand, and high investment cost. This research provides an initial understanding of current BIM adoption in Indonesia, which can be used as the basis to develop a national strategic framework for BIM adoption in Indonesia construction industry.
\end{abstract}

\section{Introduction}

The development of information technology produces a system known as Building Information Modelling (BIM). This system uses an advanced use of computers to simulate a model in planning/design, construction, operation, and maintenance phases [1-2]. There is a growing interest in using BIM because it is believed to answer all information needs of construction service providers in saving the project life cycle [3-4]. Nowadays BIM is growing day by day as well as the development of supporting applications [5].

Currently, BIM is an information technology that can learn the building, without having to actually build it first [6]. BIM has been well developed in developed countries [7], while in a developing country like Indonesia, the development of BIM is still a question which underlies researchers to analyse how BIM the implementation of $\mathrm{BIM}$ in Indonesia is and its barriers for the actors of construction in Indonesia [8-10].

This study aims to investigate BIM adoption and implementation in Indonesia construction industry, and explore challenges and opportunities related to the implementation of BIM.

\section{Overview on BIM}

BIM is considered one of the most promising developments in the AEC (Architect, Engineer, and Construction) industry [11] in terms of exploring potentials and problems related to the design and construction approach [12-13]. It is not a type of software but a process for generating and managing data from buildings [14]. Not only does it represent the geometry of a building, it also contains supporting data for the construction, fabrication, and procurement activities necessary to realize a building [11].

BIM becomes a digital representation of the physical and functional characteristics of building facilities, which is generated in three dimensions (3D) and utilises parametric intelligence to adjust their position or proportion. The 3D model also contains attributes, supports for data integration and design analysis [11]. BIM has the ability to include fourth, fifth and even sixth dimensions of modelling buildings for the process, incorporating construction scheduling (4D), pricing components and reporting (5D), and facility management (6D) [15]. There have been many uses of BIM in

*Corresponding author: jati.hatmoko@.ft.undip.ac.id 
construction projects, such as at the preconstruction phase, design phase, construction stage and postconstruction stage in European and American [16] countries, even neighbouring countries such as Singapore [17] and Hong Kong have made BIM the basis of development [15].

The concept of BIM envisions virtual construction prior to the actual physical construction, to reduce uncertainty, improve safety, solve problems, simulate and analyse potential impacts [18]. Subcontractors can include important information into the model before construction begins. Unpaid or unused items will be minimized with products delivered just-in-time rather than being garbage piling up [18].

BIM can bridge the loss of information related to project submissions from the design team, construction team and owner or operator, by allowing each group to add a reference to all the information they get during their contribution to the BIM model [19]. This can result in benefits for facility owners or operators. The building owner can find evidence of leakage in the building. Instead of exploring the physical building, he can turn to the model and see that the water valve suspect is located at which location. He can also see the valves in a certain size model, manufacturer, part number, and other information [20-21]. Dynamic information about buildings, such as sensor measurements and control signals from building systems, can also be included in BIM to support the analysis of building operations and maintenance [22-23].

\section{Research Method}

A combination of qualitative and quantitative research method has been adopted for this exploratory research. This approach is most appropriate to investigate a problem or situation to gain knowledge and deeper understanding of the object of the research.

To get more respondents, snowball sampling method has been used. This non-probabilistic method allows new respondents to be identified based on the recommendation of the previous respondents until the samples no longer develop. Semi-structured interviews with respondents were carried out for the data collection method. This data will be analysed using simple descriptive statistics.
The respondents are the construction service providers such as contractors, consultants, and project owners who are suspected of knowing or using BIM software. The total number of respondents is 20, which consist of 12 contractor companies, 4 project owners and 4 consulting firms.

Positions of respondents in this research are managers $(40 \%)$, engineers $(30 \%)$, project leaders $(15 \%)$, and top management positions, including vice president $(15 \%)$. Most of them have 5 to 10 years' experience (47\%), and the rests have less than five years' experience (35\%), and more than 10 years' experience $(18 \%)$. Based on the positions and experience, these respondents are considered very eligible, as they have a good knowledge and understanding of their own companies, particularly in terms of project information system.

\section{Results and Analysis}

\subsection{General Views on BIM}

Figure 1 shows the respondents' general views of BIM. These views were explored through several basic questions to comprehend their views, understandings, and experience of BIM. It was found that the majority of respondents $(60 \%)$ considered that BIM is considered as a new thing for their companies. As many as $47 \%$ of respondents stated that they still have no idea what BIM is, which indicates that BIM is indeed rather still unpopular to some Indonesian construction actors. They thought this situation is similar to the early days when CAD started to be used in Indonesia. It is expected that soon BIM can become popular like CAD and many more companies will use it.

Responding to a statement that 'BIM is just similar with 3D images', the majority respondents (55\%) disagreed and strongly disagreed with this statement. They see that BIM is more than just $3 \mathrm{D}$ images as there are other inputs, such as volume and even schedule in it.
BIM is still considered as a new thing

Construction practitioners still have no idea what BIM is

BIM is just similar with 3D picture

BIM is about real time collaboration

$\mathrm{BIM}$ is the future of project information

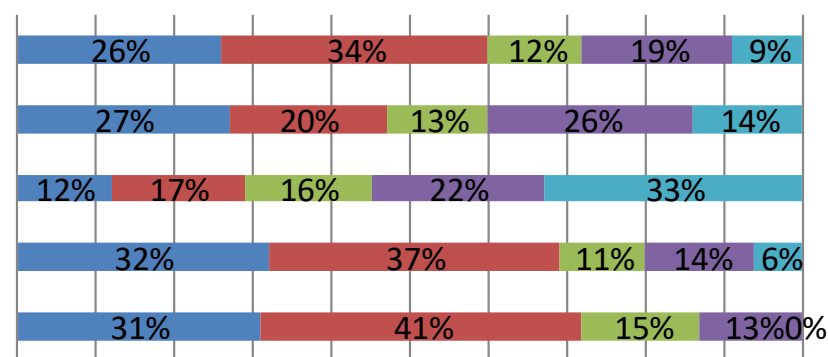

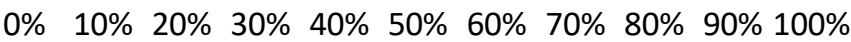

Strongly Agree $\square$ Agree $\square$ Neutral $\square$ Disagree $\quad$ Strongly Disagree

Fig. 1. Respondents' view of BIM 
A total of $69 \%$ of respondents strongly agreed and agreed that BIM is about real-time collaboration, allowing actors to communicate more effectively in executing the project. A total of $72 \%$ of respondents agreed and strongly agreed that BIM is the future of project information system. It is considered to be the future platform for communication among construction actors and provide solutions for many project problems, particularly related to long information flow which quite often causes project delays.

In terms of implementation of BIM, it was found that 12 out of 20 companies ( $60 \%$ ) have implemented BIM in their operations, while the other 8 companies (40\%) have not. Those which have implemented BIM consist of 2 consultants, 6 contractors and 4 owners (Figure 2). On the other hand, those who have not implemented BIM consist of 2 consultants and 6 contractors, most of which are government-owned companies. Evaluation on these BIM users and non-users will be described in more detailed below.

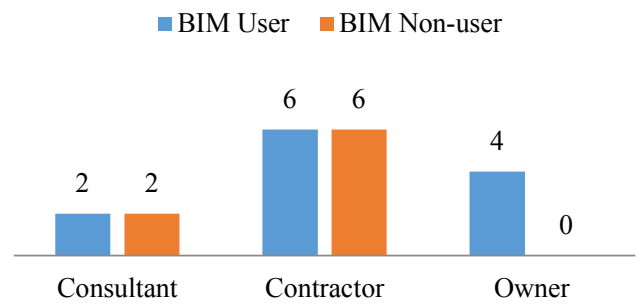

Fig. 2. Distribution of BIM users and non-users

\subsection{Evaluation on BIM users}

\subsubsection{BIM Software used by respondents}

Figure 2 shows BIM software which is used by 12 companies. The top rank is Revit $(50 \%)$, followed by Tekla (42\%), and the smallest is SmartPlant (8\%). Half of these companies have implemented BIM fully in their operation, and the other half implemented only partially, e.g. only for some projects due to requirements from clients. Tekla BIMSight and web-based were also used for sharing internally with team members or with clients.

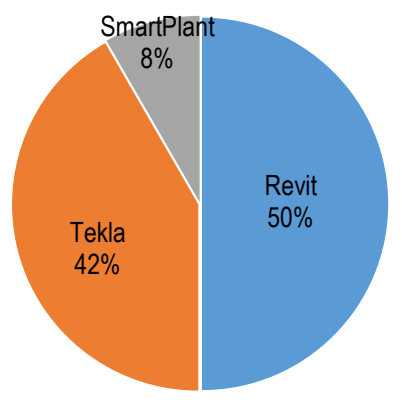

Fig. 3. Software used by respondents

\subsubsection{BIM Usage: Duration and Number of projects}

Figure 3 shows that companies that already used BIM have applied BIM mostly for more than 3 years $(58 \%), 1$ year $(8 \%)$, and 2 years $(34 \%)$.

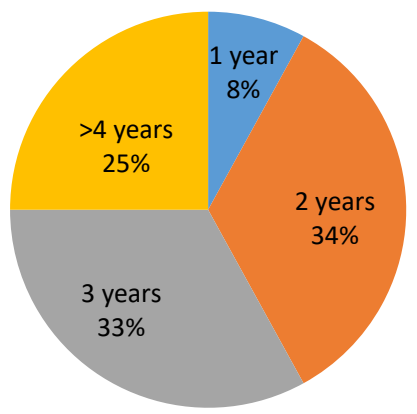

Fig. 4. Duration of the use of BIM

In terms of projects, respondents indicated that there have been quite a number of projects completed utilizing BIM software tools, i.e. 1 to 5 projects $(17 \%), 4-5$ projects $(41 \%), 6-10$ projects $(25 \%)$, and more than 10 projects (17\%) (Figure4).

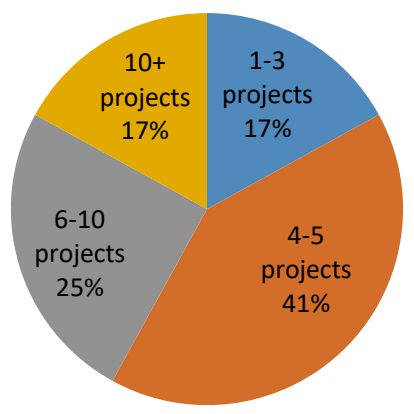

Fig. 5. Projects completed using BIM software

\subsubsection{The use of BIM in the project life cycle}

Table 1 shows the stages in which the consultants, contractors, and owners typically use BIM along the project life cycle. It was found that typically consultants used it from feasibility study, design, and construction phases. The contractors use it during design and construction phases. Typically, owners use it for the whole stages of project life cycle, starting from feasibility study, design, construction, and operation-maintenance.

Table 1. BIM usage along project life cycle

\begin{tabular}{|l|c|c|c|c|}
\hline & $\begin{array}{c}\text { Feasibility } \\
\text { Study }\end{array}$ & Design & Construction & OM \\
\hline Consultant & V & v & V & - \\
\hline Contractor & - & v & v & - \\
\hline Owner & v & v & v & v \\
\hline
\end{tabular}

\subsubsection{Reasons for using BIM}

Figure 5 shows reasons of the companies which have already used BIM in their operations, most of which are benefit-driven of BIM, i.e. software integration, planning 
certainty, faster processes than conventional, detection of design collisions, easiness of reading data, ability for project simulation, faster collaboration, reducing rework, saving project resources. From all of the reasons mentioned by respondents, software integration and planning certainty are identified as the most significant benefits that drive respondents to use BIM. While human resources efficiency and accident reduction are not considered to be very significant drivers. All of these will allow the companies to prepare the project better to achieve the project's objectives.

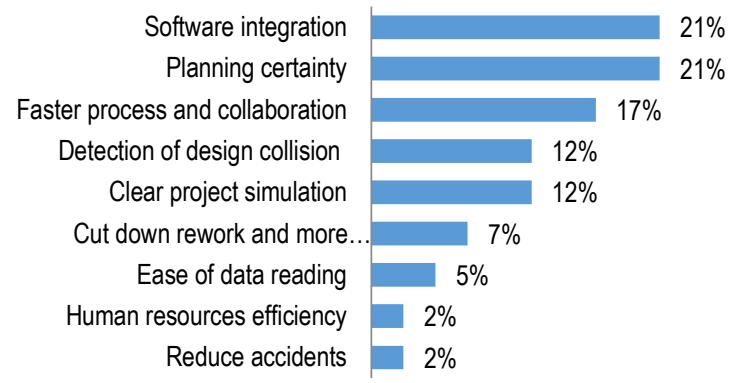

Fig. 6. Reasons for using BIM

\subsubsection{Level of BIM Adoption}

The adoption of BIM in a company may be driven by internal motivation for more efficient process and later become the norm in the organisation. On the other hand, this adoption can also be driven externally by client demands.

It was also found that half of the companies have implemented BIM fully in their operation, and the other half implemented only partially, e.g. only for some projects following the requirements from clients. Among 12 companies, $67 \%$ of the companies used BIM for sharing with clients, while the rest $33 \%$ used it for internal use only (Figure 6).

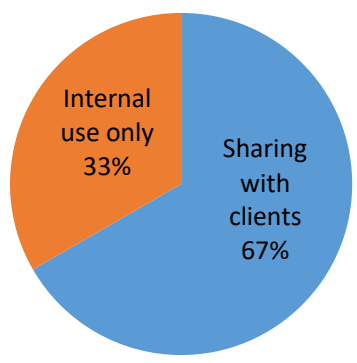

Fig. 7. BIM usage

\subsection{Evaluation on BIM non-users}

\subsubsection{Non-BIM Software used by respondents}

The research found that for non-BIM users, the most common software used are AutoCAD for design, Microsoft Project and Primavera for scheduling, and spreadsheet software such as Microsoft Excel for cost estimation and calculation. It is also known that non-BIM users are mostly still relying on 2D designs, since the current bureaucracy system of conventional document approval is also still based on 2D drawings. Most respondents said that they felt this software was still sufficient for their current needs.

\subsubsection{Barriers of BIM adoption}

Despite the benefits of implementing BIM, some barriers were perceived by the companies which have not used it. They include; high cost of investment and training, there is no need at the moment as the current technology is considered sufficient to accommodate current needs, and the absence of requests from clients (Figure7). In short, procuring and implementing BIM based software obviously needs high investment in buying the software license and employers' training.

However, the main barrier as mentioned by the respondents is that they do not really need BIM at the moment (Figure7). This is because the current method of document approval is still based on conventional 2D drawings. Thus, some respondents see no demand or need to move to BIM as their current work method is considered still sufficient.

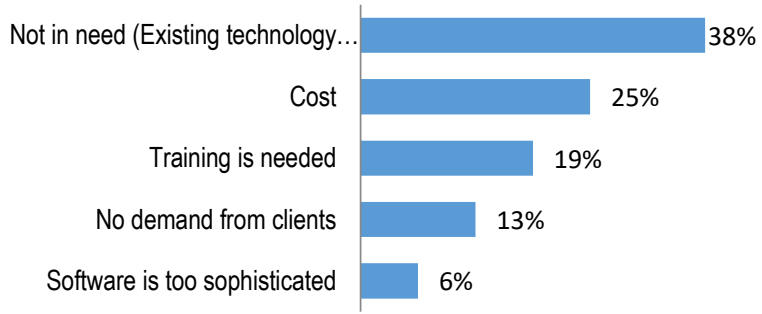

Fig. 8. Barriers of BIM adoption

\subsubsection{Planning for BIM adoption in the future}

Despite the barriers of BIM adoption, considering the abundant benefits of BIM, these companies then were asked if they would be keen on BIM adoption in the future and when it would be implemented. It was found that despite all the barriers they initially perceived, they were basically keen on BIM adoption in the near future. Interestingly, among 8 companies which have not implemented BIM, 12\% would adopt it immediately within 1 year, $75 \%$ said that they would adopt it in 2-3 years' time, and only $13 \%$ would adopt it in 4 years' time (Figure 8). This suggests that the opportunity of BIM adoption by current BIM non-user in the future is still wide open.

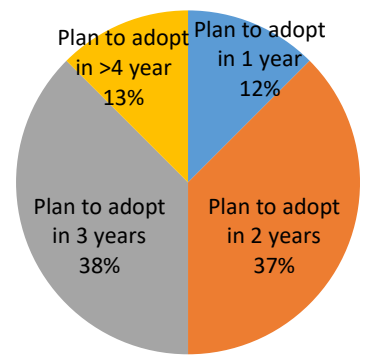

Fig. 9. Plan for BIM adoption in future 


\section{Discussions}

The decision of companies for adopting or not-adopting BIM is influenced by many factors, internally and externally. Some internal factors, include: costs, the vision of top management, the capacity of human resources, etc. External factors include government policy, current common practice in the industry, demands from clients, competition, etc.

\subsection{Looking at the current situation}

During interviews many respondents described the current project situation in Indonesia, as follows:

a. There are still many project owners who separate the process of project feasibility, planning or project design, project development, and operations and maintenance that cause no relationship or cooperation to any construction actors involved in every phase of the project lifecycle.

b. Different companies do not even have a relationship in the project cycle, e.g. between the construction actors in the planning and construction phase of the project, the construction actors at the stage of development and operation. All this quite often causes misunderstandings.

c. Two-dimensional designs are still emphasized in most projects, while three-dimensional designs are just a plus for project review, hence the shape and characters of the building is not fully comprehended.

d. Complexed bureaucracy of project documents and design approvals are still conventional. This takes more time just to wait for official signatures for approval.

e. Information management, information systems and information technology are still conventional. This causes the process will be longer and less clear information.

These conditions illustrate the state of construction in Indonesia today where most project owners have separated project feasibility, project planning or project design, project development, and operations and maintenance activities, which results in a lack of linkage or cooperation between project actors at every stage.

\subsection{Strategic challenges identified}

Based on the findings previously discussed, some strategic challenges in implementing BIM in Indonesia can be identified, i.e. the resistance to system changes, negative conception of BIM, management of resources and information, costs of investment, and changing to the internal process. They will be described as follows:

The resistance to system changes may become a significant challenge in the application of BIM. The resistance to system change from conventional bureaucracy is one of the biggest challenges in implementing BIM in Indonesia. Related to the negative conception of BIM, that BIM is still considered new to most construction actors in Indonesia, and companies find it difficult to implement it. BIM is considered as a complex system. The most difficult challenge is the lack of competence. People in the construction industry lack the skills and knowledge to be fully incorporated into the practice of this new concept.

Another challenge faced by the company is to manage resources and information, after the complete implementation of BIM and network-based integration. Companies that implement BIM must ensure that suppliers and subcontractors follow this concept as well. This involvement and the implementation of BIM by suppliers and subcontractors will lead to further management of the information. In addition, resource mapping and management are still done in traditional ways. Moreover, the company must choose an experienced and skilled partner who can support with ability, knowledge, experience and resources.

The investment for adopting BIM is considered very high to many companies, which has become a significant challenge for BIM adoption. Not to mention, the need for staff trainings and software maintenance. Despite all the benefits of BIM they will get, they must ensure that this decision is feasible in the long run.

Companies that implement BIM must change the work process internally. To make the necessary changes in the process will cost a lot. This makes the company more worried about the costs that follow the implementation of BIM.

\subsection{Recommendations to speed up BIM adoption}

The development of BIM adoption in Indonesia actually can be conducted in two ways. First, the government forces the movement of AEC industry by imposing regulations and establishing national guideline. This method was successfully applied in the UK and Singapore. Second, the adoption is driven by the industry, which is mostly fuelled by the awareness of technology development and competitive pressure, such as in Australia. Universities also play important roles for preparing future BIM experts. They will be described below.

\subsubsection{What Government can do?}

The roles of clients are very prominent to encourage the use of BIM in the project, as they can dictate the consultants or contractors to adopt it for the projects. However, as the findings suggest, some of them are still not aware of the benefits of BIM adoption for more efficient and better project deliveries. Therefore, educating clients is very important as the first step to be done. The government can take the lead as a role model by enforcing the use of BIM for certain types of government-funded projects as the initial steps. Consultants and contractors will inevitably follow this policy.

The policy to speed up BIM adoption has been implemented in some countries, e.g. UK and Singapore. UK has made the use of BIM obligatory for public projects since April 2016. The implementation of BIM in 
Singapore is progressing significantly after the government launched Singapore BIM Guide as the regulation for AEC industry. It has made it compulsory for building projects with greater than $5000 \mathrm{~m}^{2}$ to use BIM e-submissions [17].

The government may also change the bureaucracy of projects administrations based on BIM platform to make the whole process efficient, including the communication pre, during and after project deliveries.

On the other side, the government may also educate the supply side of the construction industry related to BIM adoption, i.e. consultants and contractors. The research findings suggest that some companies have already adopted it, but there are many more have not been aware of nor have adopted it. Promotion, as well as capacity building for BIM can be done by government in collaboration with BIM providers as well as associations of consultants and contractors.

\subsubsection{What can the industry players do?}

The competition in the construction industry is getting fiercer. The application of BIM technology may improve the competitiveness of national companies, and to compete with foreign companies which have started implementing BIM for a long time.

The industry players have to be open minded and prepare the organisations for BIM adoption to succesful. To face the rapid technological progress, it is necessary to increase the competence of employees and companies through the presence of a Research and Development unit in the company.

$\mathrm{BIM}$ adoption is considered providing value-added to an organisation [25-26]. The analysis of AEC industry in China recognised added value from the implementation of BIM [24]. Although this adoption can cause major changes in the way a company functions [27-30], an undeniable long-term benefit should let industry players be brave to take on the challenge.

\subsubsection{Roles of universities}

Universities also have significant roles in educating students as the future actors in the construction industry. Related departments, such as civil engineering and architecture may start to include BIM as part of their curricula to prepare for future needs of BIM experts. In the UK, for example, the infusion of BIM as a national standard for construction companies is followed by the establishing of BIM Academic Forum to support the shift in academic context [4]. BIM Academic Forum is responsible for the injection of BIM in the university, such as by providing the guide to embedding BIM in the taught module.

Universities may also develop research focusing in BIM which can support the need of the industry. They may also take part in promoting BIM to actors in the construction industry as well as supporting government in campaigning and developing a roadmap for BIM implementation in Indonesia [9, 14].

\section{Conclusions}

This study provides valuable understanding on BIM adoption and implementation in Indonesia construction industry, and explores barriers and opportunities for future, as follows:

1. The results show that 12 out of 20 sample companies $(60 \%)$ have adopted BIM fully or partially in their operation, consisting of 2 consultants, 6 contractors, and 4 owners. The BIM software used includes Revit, Tekla, and SmartPlant. They use it either for sharing with clients $(67 \%)$, or internal use only $(33 \%)$.

2. Most BIM users have implemented it more than 3 years $(58 \%)$ for $4-5$ projects $(41 \%)$, while the rest have implemented it for 1 year $(8 \%)$, and 2 years $(34 \%)$.

3. The top five reasons of adopting BIM, i.e. software integration $(21 \%)$, planning certainty $(21 \%)$, faster process and collaboration (17\%), detection of design collision (12\%), and clear project simulation (12\%).

4. The remaining of 8 companies which have not yet adopted BIM consists of 2 consultants and 6 contractors. Typically, they still used conventional non-collaborative software, such as AutoCAD, Microsoft project, Primavera and Microsoft excel.

5. Barriers of BIM adoption as perceived by the respondents include; not in the need for BIM as existing technology is considered still sufficient, high investment costs, including the training, no demand from clients, and the BIM software is seen to sophisticated to operate. Despite all the barriers, considering the huge potential benefits of BIM, most of them $(75 \%)$ were keen to adopt BIM within 2-3 years to get the benefits, while the other $12 \%$ even plan to adopt it immediately in 1 year time.

It should be recognised that the rapid development of the construction industry in this Industry 4.0 era, may influence the result of this preliminary research quite significantly within a short period. Nevertheless, this research has provided a valuable knowledge of BIM adoption in Indonesia construction industry, which at the moment otherwise may not be available.

All the respondents of this research are large class contractors or consultants, which account for only less than $10 \%$ nationally in terms of number. It is recommended for further research to look at potentials of BIM adoption particularly for medium and small class contractors and consultants. 


\section{References}

1. M. Hein, B. Sketo S. Azhar, Building information modelling (BIM): benefits, risks and challenges,(2008).

2. R. Eadie, M. Browne, H. Odeyinka, C. McKeown, and S. McNiff, BIM implementation throughout the UK construction project lifecycle, Automation in Construction, 145-151, (2013).

3. S. K. Lee, K. R. Kim, and J. H. Yu, BIM and ontology-based approach for building cost estimation, Automation in Construction, 96105, (2014).

4. Zhabrinna, The Evaluation of the Readiness of Indonesia in Adopting BIM and the Strategic Improvement by Benchmarking the Best Practice of BIM Implementation in the UK, Birmingham, MSc Dissertation (2017).

5. J. P. Martins and A. Monteiro, LicA: A BIM based automated code-checking application for water, Automation in Construction, 12-23, (2013).

6. D. Bryde, M. Broquetas, and J. M. Volm, The project benefits of Building Information Modelling (BIM), International Journal of Project Management, 971-980, (2013).

7. W. Solihin and C. Eastman, Classification of rules for automated BIM rule checking development, Automation in Construction, 69 82, (2015).

8. J. A. Liang, Kajian Terhadap Praktik Building Information Modelling pada Industri Konstruksi di Indonesia, Yogyakarta, (2015). [in Indonesian]

9. Y. Hanifah, Awareness dan Pemanfaatan BIM : Studi Eksplorasi, in Temu Ilmiah IPLBI 2016, Bandung, (2016). [in Indonesian]

10. A. Firdaus, Investigating the Mitigation of Delays in Indonesian Construction Projects Using IT Tools and Techniques, University of Birmingham, Birmingham, Dissertation (2015).

11. Eastman, What is BIM?, (2008).

12. P. E.D. Love, J. Matthews, I. Simpson, A. Hill, and O. A. Olatunji, A benefits realization management building information modelling framework for asset owners, Automation in Construction, 1-10, (2014).

13. P.E.D. Love, I. Simpson, A. Hill, and C. Standing, From justification to evaluation: building information modelling for asset owners, Automation in Construction 35, 208216, (2013).

14. V. Singh, N. Gu, and X. Wang, A theoretical framework of a BIM-based multi-disciplinary collaboration platform, Automation in Construction, 134-144, (2011).

15. P. Smith, BIM Implementation - Global Strategies, Procedia Engineering, 482-492, (2014).

16. National BIM standard - United States, National Building Information Model Standart Project Committee, (2013).

17. Building and Construction Authority, Singapore BIM Guide Version 2, Singapore, (2013).

18. D. Smith, An Introduction to Building Information Modelling (BIM), Journal of Building Information Modelling, 4-12, (2007).

19. D. Migilinskasa, V. Popovb, V. Juoceviciusc, and L. Ustinovichius, The Benefits, Obstacles and Problems of Practical BIM Implementation, Procedia Engineering, 767 774, (2013).

20. I. Motawa and A. Almarshad, A knowledgebased BIM system for building maintenance, Automation in Construction, 29, 173-182, (2013).

21. K. Sulankivi J. Nummelin, M. Kiviniemi, and T. Koppinen, Managing Building Information and client requirements in construction supply chain - contractor's view, in CIB W078W102 joint conference, Sophia Antipolis, 78102, (2011).

22. X. Liu and B. Akinci, Requirements and Evaluation of Standards for Integration of Sensor Data with Building Information Models. Caldas: O'Brien, William J., (2009).

23. D. Cao et al., Practices and effectiveness of building information modelling in construction projects in China, Automation in Construction, 113-122, (2015).

24. R. Jin, C. M. Hancock, L. Tang, and and D. Wanatowski, BIM Investment, Returns, and Risks in China's AEC Industries, Journal of Construction Engineering and Management, (2017).

25. C. S. Park, D. Y. Lee, O. S. Kwon, and X. Wang, A framework for proactive construction defect management using BIM, augmented reality and ontology-based data collection template, Automation in Construction, 22, 6171, (2013).

26. S. Zhang, J. Teizer, J. K. Lee, C. M. Eastman, and M. Venugopal, Building Information Modeling (BIM) and Safety: Automatic Safety Checking of Construction Models and Schedules, Automation in Construction, 29, 183-195, (2013).

27. A. Porwal and K. N. Hewage, Building Information Modeling (BIM) partnering framework for public construction projects, 
Automation in Construction, 31 , 204-214, (2013).

28. J.H.M. Tah, A.H. Oti, and F.H. Abanda, $A$ state-of-the-art review of built environment information modelling (BeIM), Organization, Technology and Management in Construction, 9, 1638-1654, (2017).

29. C., Teicholz, P., Sacks, R., Liston, K. Eastman, BIM Handbook: a Guide to Building Information Modeling for Owners, Managers, Designers, Engineers and Contractors. New York: John Wiley \& Sons, (2011).

30. NBS, National BIM Report 2017,(2017). 